\title{
"RAÇA E IMPÉRIO NO IMAGINÁRIO COLONIAL. COLONIAS ALEMÃS EM TERRITÓRIO AFRICANO"
}

\author{
Bárbara Caramuru
}

Resumo: Devido ao desenvolvimento industrial interno, consequentes interesses coloniais e de expansão econômica de grupos econômicos, no último terço do século XIX, o chanceler Otto von Bismarck realiza a Conferência de Berlim (1884-1885). Segundo o espírito europeu da época, esta conferência objetivava levar à África "os benefícios da civilização em geral e do comércio em particular". No entanto, o resultado desta conferência foi a divisão indiscriminada do continente, criando fronteiras fictícias, submetendo a vontade dos povos nativos. No contexto desta colonização tardia, emerge Karl Peters, agente colonial que defendeu e aplicou a teoria racialista e imperialista na "África alemã". Esta comunicação almeja analisar a prática colonial racialista de Peters. Fundamentada no marco teórico levistraussiano (raça e história), discuto alguns conceitos vinculados ao darwinismo social, que legitimou no período estudado as práticas coloniais europeias, situando-a em uma posição de "supremacia" em função de um suposto patrimônio genético herdado.

Palavras chave: África, Imperialismo, Racismo

Resumen: Debido al desarrollo industrial interno, consecuentes intereses coloniais y de expansión económica de casas comerciais, en el último tercio del siglo XIX, el canciller Otto von Bismarck realiza la Conferencia de Berlín (1884-1885). Según el espíritu europeo de la época, esta conferencia objetivaba llevar a África "los beneficios de la civilización en general y del comercio en particular". Sin embargo, el resultado de esta conferencia fue la división indiscriminada del continente, creando fronteras ficticias, sometiendo la voluntad de los pueblos nativos. En el contexto de esta colonización tardía, emerge Karl Peters, agente colonial que defendió y aplicó la teoría racialista e imperialista en "África alemana". Esta comunicación se propone analizar la práctica colonial racialista de Peters. Fundamentada en el marco teórico levistraussiano (raza e historia), discuto algunos conceptos vinculados al darwinismo social, que legitimó las prácticas coloniales europeas, situándola en una posición de "supremacia" en función de un supuesto patrimonio genético heredado.

Palabras clave: África, Imperialismo, Racismo 


\section{Introdução:}

A Alemanha em meados do século XIX havia se tornado uma grande potência. Seu desenvolvimento industrial fez dela o principal país da Europa. Através do chanceler Otto von Bismarck, por via de interesses coloniais e expansão econômica, foi realizada a Conferência de Berlim em 15 de novembro de 1884 a 26 de fevereiro de 1885 . A conferência visava levar a África "os benefícios da civilização em geral e do comércio em particular" (WESSELING, 1998). A Conferência de Berlim, de fato realizou a partilha da África entre as potências imperialistas da Europa isto implicou na composição de uma divisão do continente africano que desrespeitava as fronteiras originais e a vontade dos povos nativos. Isto será um ponto crucial no que tange a história da África.

A formação do Império Colonial Alemão se deu de modo tardio na comparação com a França ou a Inglaterra, por exemplo. A ação colonial alemã foi marcada pela atuação de Karl Peters. Este agente colonial foi o executor da teoria racialista e imperialista alemã na África, que fará dela um laboratório do nazismo.

Este ensaio tem por objetivo analisar a prática colonial e racialista de Peters. Seguindo a sugestão de Marion Brepohl, parte-se da 
vida do agente colonial - da sua primeira expedição à África em 1884 até o final de sua atuação no continente quando ele já era conhecido como "Hangpeters" (Peters, o enforcador). (BREPOHL, 2010).

Peters foi um grande propagador do ideário racialista, portanto, a análise que se segue partiu da ótica levistraussina na qual temos a discussão dos conceitos "patrimônio genético", "racionalização" e "evolucionismo cultural" dialogando com o uso do conceito de raça vinculado ao darwinismo social, ou seja, raça superior, raça selvagem e raça primitiva. A ideia de superioridade entre os homens, brancos para com os negros africanos, que vem a ser legitimado por um patrimônio genético para justificar as práticas coloniais da Europa, especificamente do agente colonial Karl Peters nas colônias alemãs da África.

O contexto onde atuou Karl Peters é o de uma Europa em meio a uma corrida imperialista que inicialmente se configura como uma dominação indireta sobre a África, porém, devido às ações de França, Portugal e Bélgica, inicia-se uma disputa incisiva pelos territórios com caráter de ocupação. Segundo o autor Uzoigwe (2010) existem várias teorias que tentam justificar esta ocupação. Desde as econômicas, que incluem esta corrida imperialista a partir da ótica que permeia a revolução industrial e a necessidade de expansão a novos mercados, de cunho marxista, apontam para este estágio como etapa final do 
capitalismo. As chamadas "teorias psicológicas", nas quais se encontrariam as de caráter missionário (levar a civilização e tutelar o indivíduo africano), e também as pautadas no darwinismo social e as que salientam uma espécie de "atavismo social" inveterado das sociedades humanas, que viriam a justificar o imperialismo. Temos ainda as teorias chamadas "diplomáticas", as quais resumidamente apontariam para vários aspetos estritamente políticos da partilha. Basicamente se agrupariam sob três princípios ligados aos processos europeus de construção nacional, seja no sentido da busca pelo prestígio nacional perdido, como seria o caso da França depois de 1871 (BRUNSCHWING, 1974), na busca de um equilíbrio de força em nível europeu (HINSLEY, 1973) e finalmente dentro de uma perspectiva de estratégia global, como seria o caso do Império Britânico (ROBINSON \& GALLAGHER, 1953). Esta última estaria avaliada pela suposta emergência de movimentos nacionalistas prematuros nas próprias colônias britânicas, as quais ameaçariam as pretensões de domínio inglês.

Temos, ainda, as teorias diplomáticas. Com as quais procuro dialogar pautando-me novamente em Uzoigwe (2010), elas versam sobre as alianças coloniais que reforçavam chefes locais. Estes acordos utilizavam as lideranças já existentes, forjando acordos de poder em que 
tais líderes se sentissem privilegiados. Desta forma, o imperialismo se utilizou das próprias estruturas locais, em muitos casos, para construir sua zona de influência e seu domínio ${ }^{1}$. Tal processo foi facilitado por conta das diferenças e conflitos étnicos/identitários, que foram de alguma forma, incentivados com um objetivo central: dividir para dominar.

Ao se comparar as várias teorias que tentam justificar esta ocupação europeia do continente africano destacam-se os muitos aspectos que as diferenciam, no entanto todas detêm como elemento comum o intuito europeu de controlar efetivamente a África. Inglaterra, França, Portugal, possuiriam um intuito de Estado em fazer-se ativo neste território. Aparentemente esta posição seria também a recémunificada Alemanha. O chanceler Otto von Bismarck, no entanto, não apoiaria de início as ações particulares no empreendimento colonial. O apoio de Bismarck a este tipo de empreendimento, muitos deles com o objetivo da autopromoção, aventureiros, (liga hanseática), como um meio de resolução a pressões políticas internas, veio mais tarde.

\footnotetext{
${ }^{1}$ Para uma reflexão pormenorizada sobre estes aspectos, vide MAMDANI, Mahmood: Ciudadano y Súbdito: África contemporánea y el legado del colonialismo tardío. Editorial Siglo XXI, México 1998
} 
Desta forma, Bismarck, presidiu a Conferência de Berlim na qual o continente africano foi dividido conforme os interesses políticos e econômicos europeus.

\section{Karl Peters: antecedentes}

Em meio a esta colonização tardia, com oportunidade de autopromoção e intuito "missionário", ou seja, de caráter civilizador, destacou-se Karl Peters, um agente colonial alemão, nascido na segunda metade do século XIX, um dentre os onze filhos de um pastor protestante, liberal e defensor da unificação da Alemanha. Peters tinha desde criança uma predileção à literatura, sendo sua infância marcada pelo contato com uma produção literária que continha heróis, grandes homens, conquistadores e aventureiros, o que pode ser relacionado à sua dedicação em construir uma trajetória de enaltecimento pessoal e de tentar se aproximar de figuras como Fernando Cortez e Cristóvão Colombo, a quem ele viria a se comparar em sua autobiografia. Ainda jovem, Peters demonstrou uma paixão pela política participando de agremiações no colégio onde estudou, formando-se, posteriormente, em licenciatura na área da história e da geografia. Sua jornada de vida 
permeia, além de seu país de origem, a Alemanha, também os Estados Unidos da América, e a Inglaterra.

A influência de seu tio, bem como sua morada temporária junto a ele, na Inglaterra foi fundamental para o contato de Peters com o imperialismo inglês e sua ideologia. Isto será decisivo ao seu propósito de fazer da Alemanha e de si mesmo marcos na política colonizadora e imperialista alemã. $\mathrm{O}$ despertar do seu interesse pela África veio por meio da influência de seu pai. Assim, Karl Peters trocara a opção de ser professor universitário por uma empreitada colonial na África Oriental, região onde posteriormente, em 1891, ele viria a se tornar governador.

Sua atuação principal foi como agente colonial alemão, difusor dos conceitos eurocêntricos e racistas que entendem o homem branco como o homem civilizador e de caráter racial superior ao nativo africano. Portanto, ele assumiu o "dever" de atuar como "governante" daquelas terras que, segundo sua perspectiva, seriam sem leis, moral ou dono, apenas tribos incivilizadas. Assim, Peters se via no direito de impor a estes o caráter civilizatório europeu (BREPOHL, 2010. pp. 144-214). 


\section{Raça e civilização no ideário europeu do século XIX}

Constata-se, especificamente na sociedade colonizadora ocidental europeia do século XIX, o uso do conceito de raça vinculado ao de superioridade biológica, cultural e no que tange a "fenômenos de civilização". Uso aqui um termo de Mauss, que se refere à civilização enquanto "espécie de meio ambiente moral no qual esta mergulhado um certo número de nações e da qual cada cultura nacional não passa de uma forma particular." (MAUSS, 1972. pp. 471-477). No período em que a colonização das áreas de domínio alemão na África foi realizada, os ideais racistas já estavam difundidos pela Europa. A historiadora Marion Brepohl afirma que, em 1884, ano da primeira expedição de Peters, o racismo já estava consumado como ideia política (BREPOHL, 2010, p. 161). Sobre a discussão acerca da política racial de Peters, bem como a definição do conceito de raça, partirei do conceito racialista que buscou estabelecer uma relação hierárquica de superioridade entre os homens, usado para justificar a política imperialista da Europa em suas colônias. Segundo Banton:

A terceira idéia, a de raça, prometia em primeiro lugar que cada tipo racial tomaria posse do território que naturalmente lhe fosse mais adequado, mas este conceito deu lugar à crença de que os brancos tinham herdado uma 
superioridade que os habilitava a estabelecer o seu poder em todas as regiões do mundo. A previsão também não foi cumprida, quer numa quer noutra forma. (...) o aparecimento de uma base biológica para as teorias raciais desintegrou-se. (BANTON, 1977).

Por meio desta ótica de superioridade racial, a Alemanha, através de Peters atuou nas colônias africanas a partir de uma ideologia de subjugação do indivíduo negro. Segundo Frantz Fanon (FANON, 1986), o imperialismo atuaria como uma política ideológica de inferiorização do indivíduo, submetendo-o psicologicamente a dominação e criando, portanto, uma relação de subjetividade entre o colonizador e o colonizado: a partir do imaginário e do sentimento criase uma estrutura de dominação em que o branco, mesmo em minoria, vê-se como líder, como chefe, e o negro, mesmo em grande maioria, "entender-se-ia" como inferior, ora desejando embranquecer, ora entendendo-se em um lugar de inferioridade e submissão. Desta forma, observamos que a política imperialista encontra-se moldada por uma estrutura tão envolvente que, como defende Fanon, não há formas brandas ou pesadas de racismo. Esta estrutura ideológica, para além dos pilares econômicos, cria um imaginário "colonizador" que fez pessoas se deslocarem de seus países de origem para viver uma aventura, obter 
um rápido enriquecimento, além de cumprir seu dever de levar a "civilização" ao outro: o selvagem.

Em contrapartida, tal pensamento fez do nativo o "selvagem e incivilizado", que deve conscientizar-se da sua posição num patamar inferior, de seu papel submisso e ainda, em certos casos, da necessidade de se "civilizar" e de "embranquecer", sendo "civilizar" entendido como a adoção de um modelo sociocultural e econômico europeu. Este imperialismo, mesmo que gerado por vias econômicas, torna-se uma estrutura enraizada subjetivamente e de difícil rompimento em virtude de seu caráter de dominação psicológica, se perpetuando no imaginário africano mesmo após a descolonização, como aponta Frantz Fanon ${ }^{2}$ em sua obra "Pele Negra, Máscaras Brancas":

Se ele se encontra a tal ponto submerso pelo desejo de ser branco, é que vive em uma sociedade que torna possível seu complexo de inferioridade, em uma sociedade cuja consistência depende da manutenção desse complexo, em uma sociedade que afirma a superioridade de uma raça; é na medida exata em que esta sociedade lhe causa

2 Frantz Fanon, médico, intelectual e psiquiatra. Nascido em 20 de Julho de 1925 na Martinica - Bethesda Washington 6 de dezembro de 1961. Fora um assíduo militante na luta pela independência da Argélia. Sua obra aqui citada "Pele Negra Mascaras Brancas“, publicada inicialmente em 1952, faz referência ao processo de colonização européia na Africa e os desdobramentos deste, principalmente no que tange a psique humana. 
dificuldades que ele é colocado em uma situação neurótica. (FANON, 1986. p. 95)

Marion Brepohl, em seu livro "Imaginação Literária e Política: Os Alemães e o Imperialismo 1880/1945" realizou uma extensa análise refletindo sobre as diversas facetas deste agente, indo desde o Karl Peters ainda jovem, atraído pelo imperialismo inglês por meio de artigos jornalísticos que propagandeiam o projeto colonial, ao Peters maduro, que por meio de uma reunião de suas memórias buscara ser retratado como uma figura de destaque na História, e ainda o oficial visto através da ótica do autor Balder Olden (BREPOHL, 2010). Nessa comunicação trabalharei apenas com a fase de Peters enquanto agente colonial, executor da política racial e imperialista nas regiões que virariam colônias de ocupação alemã.

Segundo Brepohl, Peters era um assíduo leitor da imprensa colonial inglesa, porém não tinha experiência prática, nem apoio do Estado, apenas uma ambição individual. Essa mesma ambição definiu sua atuação, tentando convencer os governos a financiá-lo na conquista da África oriental, e, desta forma, realizar seu desejo de tornar a empresa colonial em um ato exclusivo de realização pessoal. Porém, com o passar do tempo seu envolvimento com uma política racista de dominação e sua vivência iria despertar uma segunda fase de atuação, 
agora para além de um sujeito desenvolvendo suas ambições pessoais e o caráter "civilizatório" do imperialismo inglês, mas da prática de uma ideologia com que já tinha contato e da qual ele via-se embebido: o racismo. Assim, iria se desenvolver um longo período em que o agente teve por intuito desumanizar o negro. Em 1886, ao ser investigado por conta de diversas denúncias de violência enviadas diretamente ao parlamento, fora afastado de seu cargo com a justificativa de ter cometido atrocidades contra africanos, dentre estes, incluíam-se sua concubina e um dos seus criados. Passando a ser conhecido como Hängepeters, Peters, o enforcador, ou ainda "Mikono wa Daтu: o homem que tinha sangue nas mãos", como era conhecido em Tanganica. (BREPOHL, 2010. pp. 174 e 187).

o agente colonial, apesar de conviver com o nativo cotidianamente, tornou-se indiferente ao povo que governava, uma vez que o fazia em nome dos interesses econômicos e militares de sua nação, uma nação que por direito de origem era vista como tendo o nível mais alto de civilização. (BREPOHL, 2010. p 156)

\section{Peters e seu "ódio civilizador"}


Karl Peters deixa três conjuntos de atos discursivos, nos quais faz desde a propaganda colonial alemã e de suas práticas, até uma alusão a sua memória, que seria uma memória voluntária, uma criação do passado, produzida com certo intuito: o de fazer da memória, fazer história. (SEIXAS, 2004. p. 42). A partir deste conjunto de fontes mobilizadas, tratadas dentro do marco teórico levistraussiano, identifica-se que há nelas, para além da propaganda colonial, uma disseminação da ideia de superioridade de uma raça branca e um fomento ao ódio ao homem negro, africano. Na forma como se constroem os atos discursivos do autor, busca-se a desqualificação do nativo africano, definindo-o com características similares a um animal: desprovido de razão ou moral, dotado de "bestialidade". Nelas observam-se as ações práticas do agente colonial, as quais mais tarde seriam consideradas uma espécie de base do laboratório nazista experimentado na África a partir de sua primeira expedição em 1884. Alguns trechos são transcritos pela historiadora Brepohl: ${ }^{3}$

Sobre a questão do trabalho africano

3 As fontes foram utilizadas a partir da obra Imaginação Literária e política: Os alemães e o imperialismo 1880-1945 em que a autora faz uma análise sobre a literatura de Peters. 
Eu tenho repetido que a população africana é dotada pela natureza de forca muscular muito resistente, estando apta e exercer trabalho braçal como nenhum outro povo do mundo [...] Mas se nós temos a obrigação de servir ao Estado, porque não prever as subespécies alguns deveres, porque desaprovar isso, se elas há mil anos anos se acostumaram ao trabalho e foram predestinadas ao trabalho braçal?

Como tratar os negros do jeito que os fanáticos por negros querem, se os negros mesmo se deixam tiranizar por déspotas?[...] Como aos pretos, que são moral e racialmente inferiores, sejam e eles dadas certas vantagens? [...]

[...] Não é possível empregar força militar na África usando os africanos. Os negros não tem coragem moral. Sua coragem física também é fraca. Eles só se encorajam ao som de seus gritos e seus tambores. [...] São cheios de bestialidade e brutalidade, são sanguinários. Indiferença com respeito a dor do outro também [...] é característica desta raca.

Ele é escravo nato que precisa de seu déspota como um viciado em ópio precisa de seu cachimbo. É mentiroso, ladrão, falso e pérfido [...]". (BREPOHL, 2010, p. 169171)

\section{A questão racial na África do sul}

O que se quer reparar, do ponto de vista histórico, e que o preto e produto de sua terra; a ele e nao aoS europeus pertence a África, como ao elefante e ao hipopótamo, aos diversos felinos. E os etíopes berram " a terra dos pretos para os pretos" . [...] No entanto até o liberalismo inglês, que inicialmente deu de presente a auto-administração, 
retirou rapidamente esta proposta, anunciando a prevalência do elemento bôer... Porque os bôer tem o direito natural de se estabelecer ali, pela lei do mais forte[...] Eu nao digo África para. Os africanos, mas África para os africânders " (BREPOHL, 2010, p.170).

Além de tais afirmações, Peters ainda afirma que os negros são os culpados pela miscigenação, a partir do momento em que estes “estupram as mulheres brancas" que, segundo ele, teriam aversão natural aos negros. "[...] Como evitar a miscigenação? Proibir legalmente os casamentos mistos? Mas quão frágeis são as leis face aos instintos naturais[...] E evidente que os bancos repelem, naturalmente, em seus sentimentos os negros, mas os negros violentam as mulheres e meninas brancas.". Vemos nitidamente que o intuito das obras de Peters não é só propagandear a ideologia racial, ou o colonialismo alemão, mas também a ideia explicita de desumanizar o negro, e assim também justificar a atitude do branco. Para Peters, quando o branco age de forma violenta com o negro, visto pelo agente como "objeto negro", ele está exercendo um direito natural e tem total autonomia, suas ações que são legitimadas por uma ideologia que o respalda: o "projeto civilizatório". A atuação de Peters parte de uma visão que considera o indivíduo negro como inferior, subjugável, desta forma, para ele é necessário o totalitarismo do déspota. Como já 
observamos, a questão vai além do darwinismo social, é muito mais uma questão de fomentar deliberadamente o sentimento de ódio ao que o agente caracteriza como "raça negra".

Relacionado a este ponto (também tomando com referência analítica Lévi-Strauss) parte-se do entendimento de que Peters não condiz com a especificidade de um déspota louco, ou a de um ator social violento e com prazer em atuar enquanto homicida. $\mathrm{O}$ entendimento é que Peters era agente de uma estrutura: o imperialismo europeu, um imperialismo marcado a "ferro e fogo", que constituiu suas bases nas atuações de figuras como Karl Peters, instrumentos diretos do maquinário imperialista e que se constituíram na África através da justificativa ideológica da teoria do darwinismo social. Um suposto "racismo científico", que nas décadas de 30 e 40 do século XX será propagado pela ideologia nazista.

\section{A insustentabilidade da raça como categoria biológica}

O antropólogo Claude Lévi-Strauss, publicou em 1952 o ensaio "Raça e História", (traduzido ao português em 1983) a pedido da UNESCO para contribuir ao programa de luta contra o racismo, devido ao contexto pós-segunda Guerra Mundial e em meio ao processo de 
Revista Vernáculo, $n^{o} 30,2^{\circ}$ sem/2012

descolonização da África, aponta para a impossibilidade de dialogar com o passado utilizando conceitos evolucionistas e, assim, criar linhas genealógicas que estabelecessem uma hereditariedade entre a sociedade greco-romana e a sociedade europeia, a qual, por sua vez, pudesse justificar qualquer superioridade biológica ou imposição e violências, exemplificadas pelo autoritarismo de Peters, a outras sociedades e culturas, consideradas "primitivas" ou inferiores. O autor defende um argumento chave para a essa discussão: "Não é da competência de um etnólogo tentar dizer o que é, ou o que não é, uma raça...”. (LÉVISTRAUSS, 1983, p. 21) No entanto, observa que existem algumas linhas de pensamento divergentes entre os antropólogos a respeito dessa afirmação. A primeira destas linhas de pensamento, segundo LéviStrauss, acredita que a espécie humana se dividiu em "subespécies", com mescla de traços, antigos e modernos, gerando esta diversidade étnica que permanece atualmente. A segunda visão, por sua vez, defende que o isolamento genético é mais recente e que as diferenças observáveis não tinham sua origem dada por "desvios acidentais entre traços desprovidos de valor adaptativo" (LÉVI-STRAUSS, 1983, p.20).

Entretanto, Gobineau, autor ligado à primeira hipótese, já defendia que a diferença racial era um fenômeno não observável. Após 
diversas discussões posteriormente aceitas concluiu-se que este debate não era de fato sobre a diversidade das raças e sim a respeito das culturas. Há um equívoco no qual se confundiu a noção biológica com a sociológica. Lévi-Strauss defende que a diversidade existe paralela a questões biológicas, argumentando que "Todos os traços sucessivamente invocados para definir diferenças raciais se revelaram, uns a seguir aos outros, ligados a fenômenos de adaptação [...]”. (LÉVI-STRAUSS, 1983, p.24) Desta forma ele questiona a interface entre cultura e raça, pois precisamente pode-se definir cultura, mas não raça. Ele cita, então, a diversidade de culturas e a diferença entre os aspectos físicos existentes entre estas. O antropólogo argumenta que é impossível estabelecer a existência de uma relação entre diferenças físicas e diferenças culturais, pois nem os geneticistas são capazes de fazer esta ponte entre condutas complexas, que conferem diferenças “físicas" e cultura. Segundo Lévi-Strauss, não necessitamos desse tipo de comparações.

Outra questão trazida pelo autor é referente ao uso de um "patrimônio genético", para legitimação da superioridade de certa cultura, que explanamos acima a partir de Banton. No capítulo "Raça e História”, o autor Lévi-Strauss, julga impossível a análise das culturas sob a ótica evolucionista, citando que o desenvolvimento é, inclusive, 
incentivado com as relações (contatos) de umas com as outras. Ressalta, também, a dificuldade da classificação racial/social, que pode nos remeter a conceitos racistas, reacendendo-os. No tópico "Etnocentrismo", o autor argumenta sobre a complexidade da aceitação da diversidade cultural, o que pode levar a uma abordagem em termos evolucionistas, de superioridade ou a generalização. Não há a possibilidade de colocá-los em uma linha de igualdade, pois, devido à pluralidade e diversidade social/cultural, cada cultura tem comportamentos específicos e suas particularidades, bem como seu desenvolvimento próprio. $\mathrm{O}$ autor faz, ainda, ressalvas quanto à interpretação dessas culturas nas sociedades contemporâneas, principalmente nos casos onde a possibilidade de diálogo com as culturas estudadas não mais existe, por estarem, muitas vezes, já extintas. Questiona também a ideia de progresso, traçando uma série de exemplificações que negam este evolucionismo cultural. Com esta análise, fica nítido que as questões colocadas pelo racismo "científico", e propagandeadas por Karl Peters, que apontam para a "bestialidade" do negro, sua selvageria, violência e seu encorajamento apenas ao som de seus tambores, são exemplos evidentes da visão e da ideia desenvolvimentista, etapista e progressista do período em que o agente atuou e de como ele se via imbuído por esta ideologia. 
Quanto à análise da Arte Rupestre, Lévi-Strauss afirma ser “[...] uma das interpretações mais populares, entre as que se inspiram o evolucionismo cultural", fazendo ainda o seguinte comentário:

Podemos ficar tentados a ver neste último traço a origem da arte europeia; mas mesmo isto seria inexato, já que, no mesmo território a arte paleolítica foi seguida por outras formas que não tinham o mesmo caráter; a continuidade da localização geográfica não altera em nada o fato de que, no mesmo solo, se tenham sucedido populações diferentes, ignorantes ou descuidadas das obras de seus antecessores, e trazendo, cada uma, crenças, técnicas e estilos opostos. (LÉVI-STRAUSS, 1976)

O autor afirma, na sequência que, mais importante que catalogar os traços das sociedades, é entender suas relações e buscar interpretálas, como o caso da cultura "estacionária", caracterizada pelo autor como uma complexidade de sistemas. Lévi-Strauss também escreve em "A Colaboração das Culturas" sobre a importância do contato intercultural para uma suposta "evolução" das mesmas, afirmando que a ausência de tal contato reduz a diversidade, gerando a homogeneização. Outro tópico que cabe a essa problematização, seria o "Lugar da Civilização Ocidental", onde o autor discute a ideia de superioridade da cultura ocidental, e a imposição dela sobre as outras culturas. Sem pretender desenvolver uma análise de temas já bastante explorados, 
tanto por Lévi-Strauss, quanto por diversos antropólogos e sociólogos, bem como por outros campos que têm os estudos sociais e culturais como seu objeto de pesquisa, remeto-me a parte da discussão de três tópicos abordados pelo autor.

A análise do antropólogo aponta para os problemas nas interpretações sobre as sociedades antigas. Através dessa crítica, podemos identificar o uso do passado e de algumas interpretações que promovem a legitimação da superioridade, tanto cultural, quanto racial de certas sociedades e culturas, as quais, muitas vezes, encobririam objetivos político-ideológicos. O que é seguramente ilustrado no caso de Peters. Portanto, para Lévi-Strauss, o uso dos conceitos de "patrimônio genético", "racialização", "progresso" e "evolucionismo cultural", além de todo o darwinismo social que está envolvido em tais pensamentos, e que foram propagandeadas de maneira aberta por Karl Peters durante sua vida como agente colonial, legitimando uma superioridade cultural eurocêntrica, a qual justificaria toda a empresa imperial, seriam desde um ponto de vista antropológico, injustificável. Ao contrário de classificar as sociedades em conceitos raciais, deve-se priorizar o entendimento destas sociedades em todas as suas pluralidades, diversidades e complexidades. Peters, ao fazer uma apropriação do discurso racista e reproduzi-lo de tal maneira até se 
tornar no conhecido "Hangepeters", atuava apenas legitimando uma política historicamente repleta de exemplos, a política imperialista praticada na África.

O discurso e atuação do agente Karl Peters se relacionam com a estrutura imperialista vigente na época, bem como com sua ideologia e também ao darwinismo social e conceitos desenvolvidos a partir dele. Peters não representa uma figura isolada: suas ações são agenciamentos de uma estrutura imperialista desse período. A sua convicção a respeito de uma superioridade racial do homem branco em relação ao homem negro e as outras raças, consideradas pelo agente como incivilizadas e ou biologicamente inferiores, construídas a partir de teorias relacionadas ao darwinismo social, fez de Peters um exemplo a ser seguido no período de ascensão nazista na Alemanha, momento em que ele era considerado um herói.

\section{Bibliografia}

BANTON, M. A idéia de Raça. São Paulo. Edições 70. Martins Fontes, 1977

BREPOHL, M. Imaginação Literária e Política: os alemães e o imperialismo 1880-1945. Uberlândia EDUFU, 2010 
Revista Vernáculo, $n^{o} 30,2^{\circ}$ sem/2012

BRUNSCHWIG, H. A partilha da África negra. Perspectiva, São Paulo, 1974

FANON. F. Pele Negra. Mascaras Brancas. Rio de Janeiro: Editora Fator, 1986

GALLAGHER, J. \& ROBINSON, R. "The Imperialism of Free Trade". In The Economic History Review, Second series, Vol. VI, no. 1, 1953, pp. 1-15

HINSLEY, F. H. Nationalism and the International System. Oceana Publications, New York, 1973.

LEVI-STRAUSS, C. Antropologia Estrutural Dois: Raça e História, o duplo sentido do progresso. Tempo Brasileiro: Rio de Janeiro, 1976 . O Olhar Distanciado. Lisboa Eds. 79, 1983.

.Tristes Trópicos: Como se faz um Etnógrafo. São

Paulo: Anhembi, 1957

MAMDANI, Mahmood. Ciudadano y Súbdito: África contemporánea y el legado Del colonialismo tardío. Editorial Siglo XXI, México 1998. 
Revista Vernáculo, $n^{o} 30,2^{\circ}$ sem/2012

MAUSS, M. Sociedad y Ciencias Sociales. Barcelona: Breve Biblioteca de Reforma Barral Editores, 1972

SEIXAS, J. Percursos de memórias em terras de história: problemáticas atuais. In: BRESCIANI, M. Stella; NAXARA, M. Memória e ressentimento: indagações sobre uma questão sensível. Campinas, SP: Editora da Unicamp, 2004, pp. 37-58

UZOIGWE, Godfry N. "Partilha européia e conquista da África: apanhado geral". In: BoaHen, Albert Adu (Ed.): História Geral da África, Vol. VII. São Paulo: Ática/UNESCO, 1991, pp. 21-50.

WESSELING, H.L Dividir para dominar: a partilha da Africa (1880-1914). Editora : UFRJ: Editora Revan. Rio de Janeiro, 1998 